\title{
Staphylococcus aureus bacteriuria as a prognosticator for outcome of Staphylococcus aureus bacteremia: a case-control study
}

Shingo Chihara ${ }^{*}$, Kyle J Popovich ${ }^{2,3}$, Robert A Weinstein ${ }^{2,3}$, Bala Hota ${ }^{2,3}$

\begin{abstract}
Background: When Staphylococcus aureus is isolated in urine, it is thought to usually represent hematogenous spread. Because such spread might have special clinical significance, we evaluated predictors and outcomes of S. aureus bacteriuria among patients with $S$. aureus bacteremia.

Methods: A case-control study was performed at John H. Stroger Jr. Hospital of Cook County among adult inpatients during January 2002-December 2006. Cases and controls had positive and negative urine cultures, respectively, for S. aureus, within 72 hours of positive blood culture for $S$. aureus. Controls were sampled randomly in a 1:4 ratio. Univariate and multivariable logistic regression analyses were done.

Results: Overall, 59\% of patients were African-American, 12\% died, 56\% of infections had community-onset infections, and 58\% were infected with methicillin-susceptible S. aureus (MSSA). Among 61 cases and 247 controls, predictors of $S$. aureus bacteriuria on multivariate analysis were urological surgery $(O R=3.4, p=0.06)$ and genitourinary infection $(O R=9.2, p=0.002)$. Among patients who died, there were significantly more patients with bacteriuria than among patients who survived (39\% vs. 17\%; $p=0.002$ ). In multiple Cox regression analysis, death risks in bacteremic patients were bacteriuria (hazard ratio 2.9, Cl 1.4-5.9, $\mathrm{p}=0.004$ ), bladder catheter use (2.0, 1.0-4.0, $\mathrm{p}=0.06)$, and Charlson score $(1.1,1.1-1.3, p=0.02)$. Neither length of stay nor methicillin-resistant Staphylococcus aureus (MRSA) infection was a predictor of $S$. aureus bacteriuria or death.

Conclusions: Among patients with S. aureus bacteremia, those with S. aureus bacteriuria had 3-fold higher mortality than those without bacteriuria, even after adjustment for comorbidities. Bacteriuria may identify patients with more severe bacteremia, who are at risk of worse outcomes.
\end{abstract}

\section{Background}

Bacteriuria with Staphylococcus aureus is postulated to occur through a limited number of mechanismsprimarily ascending spread after instrumentation (e.g., urologic procedures or urethral catheterization) or hematogenous seeding of the genitourinary tract. The finding by Lee et al., that bacteremia is strongly associated with bacteriuria among patients infected with $S$. aureus, supports the notion that bacteremia is an important precursor for bacteriuria [1]. What is less clear, however, is whether in patients with $S$. aureus

\footnotetext{
* Correspondence: shingo_chihara@rush.edu

'Department of Clinical Laboratory Medicine, Dokkyo Medical University, Tochigi, Japan
}

(c) 2010 Chihara et al; licensee BioMed Central Ltd. This is an Open Access article distributed under the terms of the Creative Commons Attribution License (http://creativecommons.org/licenses/by/2.0), which permits unrestricted use, distribution, and reproduction in any medium, provided the original work is properly cited. any prognostic significance.

Among patients with $S$. aureus bacteremia, there are many prognostic factors, including host factors or comorbidities (age [2-10], Charlson score [2,11], immunosuppression [4], alcoholism [4], hemodialysis [4], acute renal failure [4], diabetes mellitus [8], recent hospitalization [11], mechanical ventilation [5], and acute severity of illness [12]); pathogen-specific factors (MRSA $[3,13]$ superantigenic toxin production [14]); or characteristics of clinical presentation or management (meningitis [13] or altered mental status [11,12], communityacquired infection [4], severe sepsis or septic shock $[3,4,6,7]$, lack of an infectious disease consult $[4,15]$, foci of infection [16], daily dose of penicillinase-stable prior antibiotic therapy [6], unknown [8] or persisting 
penicillin < 4 grams [16], and inappropriate empiric treatment $[6,12]$ or duration of treatment $<14$ days [16]). The relation of occurrence of bacteriuria to outcome has been postulated [17], but the interactions with other risk factors warrant investigation. That bacteriuria might be a predictor of worse outcome in S. aureus bacteremia has biologic plausibility. For example, several innate defense mechanisms exist that prevent the development of urinary tract seeding in bacteremic patients: defensins, Toll-like receptor 4 , and chemokine receptor CXCR1 $[18,19]$, and these innate defenses may be overcome and the urinary tract seeded in the setting of higher bacterial loads [20].

Over the last 20 years, MRSA has emerged as an important cause of nosocomial bacteremia [21], and significant increases in the incidence of MRSA infections in community patients have been observed in the past few years [22-24]. Methicillin-resistance is a major risk for increased morbidity and mortality in S. aureus infection. Given the increasing burden of infection by community-associated MRSA (CA-MRSA) infections [22-24] and the suggestion that CA-MRSA strains may have greater virulence, predictors of morbidity and mortality are essential for allocation of clinical infections.

We hypothesized that for patients with $S$. aureus bacteremia, bacteriuria is an important marker of disease severity and predictor of worse outcomes. We examined this hypothesis by evaluating outcomes of $S$. aureus bacteremia in patients with and without bacteriuria. We also examined the impact of methicillin-resistance on outcomes among patients with $S$. aureus bacteremia with and without bacteriuria. Finally, using our cohort, we examined the predictors of bacteriuria.

\section{Methods}

\section{Setting}

A case-control study was performed for patients admitted to John H. Stroger Jr. Hospital of Cook County, a 464-bed inner-city safety-net hospital in Chicago, Illinois. The institutional review board reviewed the study and deemed it exempt from review.

\section{Study Design and Definitions}

Our study included in-patients during January 2002 through December 2006. Cases were patients who had a positive urine culture for $S$. aureus within 72 hours of a positive blood culture for $S$. aureus. Controls were patients who had a negative urine culture for $S$. aureus within 72 hours of a positive blood culture $S$. aureus. Control patients were randomly sampled from all eligible patients with $S$. aureus bacteremia but without bacteriuria (i.e., with negative urine cultures), with the aim of 4 controls per case. Subsequently, chart reviews were performed and exclusion criteria were applied to sampled putative cases and controls to create a cohort for analysis.

Patients who were younger than age 18 years, who were seen only in the emergency department or in the clinic, or who did not have a urine culture performed within 72 hours of the positive blood cultures, were excluded. Only the first episode of $S$. aureus bacteremia per admission was assessed.

Using electronic data and chart review, we collected demographic and clinical data including mortality, ICU admission, length of stay, age, race, sex, Charlson score [25], comorbidities (HIV, diabetes mellitus, end stage renal disease requiring hemodialysis), alcoholism, intravenous drug use, presence of indwelling bladder catheter at the time of culture, previous urological procedure, duration of fever, duration of bloodstream infection, urinary symptoms, duration of chief complaint, organs and sites infected by $S$. aureus decided by the clinician, evidence of foreign material, susceptibilities of $S$. aureus, and time to appropriate antimicrobial therapy. For patients who died during their hospitalization, death was attributed to the bacteremia if so noted by the patient's discharge diagnosis or when there was a positive blood culture within 1 week preceding death.

S. aureus was deemed hospital-acquired if illness had onset $>72$ hours after hospital admission. Cultures that turned positive within 72 hours of admission-communityonset-were divided into 2 groups: healthcare-associated infection was defined based on history of hospitalization, surgery, dialysis, or residence in a long-term care facility within 1 year or a presence of an indwelling catheter or percutaneous medical device (e.g., tracheostomy tube, gastrostomy tube, or bladder catheter) or a prior MRSA infection; patients with community-acquired infection did not have any of these risk factors [26].

\section{Statistical Methods}

Categorical variables were examined with chi-square analysis and continuous variables were analyzed with the independent samples $t$ test. For multivariable analysis, statistically important factors with $\mathrm{p}$ values $<0.10$ on univariate analysis were included in initial models, and Charlson score was included a priori based on the strong association between comorbidities and death, and our desire to appropriately adjust for comorbidities in our analysis. We used Cox proportional hazards regression analysis to assess the association of bacteriuria with time to $S$. aureus death or hospital discharge, adjusted for suspected effect modifiers as identified in univariate analysis. Explanatory variables were evaluated for adherence to the proportional hazards assumption. To assess the multivariable predictors of bacteriuria, logistic regression was used. Data analysis was performed using SPSS software (version 15.0, Chicago, IL). 
Table 1 Univariate analysis of predictors of death during admission among patients with S. aureus bacteremia and a contemporaneous urine culture obtained ${ }^{a}$

\begin{tabular}{|c|c|c|c|c|}
\hline Risk Factor $^{b}$ & Death during admission & No death during admission & OR $(95 \% \mathrm{Cl})$ & $P$ value \\
\hline N & 36 & 253 & & \\
\hline \multicolumn{5}{|l|}{ Demographics } \\
\hline Male & $22(61)$ & $176(70)$ & & 0.31 \\
\hline Race/Ethnicity & & & & 0.46 \\
\hline Black & $22(61)$ & $145(50)$ & & \\
\hline Hispanic & $9(25)$ & $44(15)$ & & \\
\hline Other race & $2(6)$ & $23(8)$ & & \\
\hline White & $3(8)$ & $41(14)$ & & \\
\hline Age & $51.6(15.8)$ & $47.6(15.3)$ & & 0.15 \\
\hline \multicolumn{5}{|l|}{ Microbiological Factors } \\
\hline Epidemiologic risk & & & & 0.76 \\
\hline Community associated & $11(31)$ & $69(27)$ & & \\
\hline Healthcare associated & $8(22)$ & $71(28)$ & & \\
\hline Hospital onset & $17(47)$ & $113(45)$ & & \\
\hline$\overline{M R S A}$ & $17(47)$ & $103(41)$ & & 0.46 \\
\hline Urine culture positive & $14(39)$ & $43(17)$ & $3.11(1.47-6.55)$ & 0.002 \\
\hline \multicolumn{5}{|l|}{ Clinical Factors } \\
\hline HIV & $6(17)$ & $28(11)$ & & 0.32 \\
\hline Bladder catheter & $19(53)$ & $86(34)$ & $2.17(1.07-4.39)$ & 0.03 \\
\hline Charlson score & 2.84 & 2.04 & & 0.22 \\
\hline Hemodialysis & $1(3)$ & $26(11)$ & $0.24(0.03-1.90)$ & 0.15 \\
\hline Immunosuppressed & $8(22)$ & $45(18)$ & & 0.52 \\
\hline Urological surgery & $0(0)$ & $13(5)$ & & 0.16 \\
\hline$\overline{\mathrm{DM}}$ & $13(36)$ & $70(28)$ & & 0.30 \\
\hline IVDA & $4(11)$ & $42(17)$ & & 0.40 \\
\hline Prosthetic device & $3(8)$ & $63(25)$ & $0.27(0.08-0.92)$ & 0.03 \\
\hline Alcoholism & $7(19)$ & $40(16)$ & & 0.58 \\
\hline $\mathrm{ID}_{\mathrm{D}}$ consult or management ${ }^{\mathrm{c}}$ & $18(50)$ & $128(60)$ & & 0.25 \\
\hline Line/phlebitis & $2(6)$ & $56(22)$ & $0.21(0.05-0.89)$ & 0.02 \\
\hline Skin soft tissue infection & $7(19)$ & $50(20)$ & & 0.96 \\
\hline Bone/joint infection & $2(6)$ & $25(25)$ & & 0.40 \\
\hline Pulmonary infection & $6(17)$ & $35(14)$ & & 0.65 \\
\hline GU infection & $0(0)$ & $22(9)$ & & 0.05 \\
\hline Incubation Period & $26.8(67.4)$ & $12.4(24.0)$ & & 0.21 \\
\hline \multicolumn{5}{|l|}{ Outcome } \\
\hline Fever days & $2.7(4.8)$ & $3.7(5.0)$ & & 0.11 \\
\hline Time to effective therapy & 1.06 (2.6) days & 1.8 (3.7) days & & 0.12 \\
\hline Length of stay after culture & 10.1 (11.3) days & 13.5 (14.1) days & & 0.17 \\
\hline
\end{tabular}

Footnotes: ${ }^{a}$ Contemporaneous urine cultures are performed within 72 hours of the blood culture. ${ }^{b}$ Data represent count (\%) and mean (standard deviation) for count and continuous data, respectively. 'Patient management was either primarily by infectious diseases clinician or with infectious diseases consultation.

\section{Results}

During 5 years (January 1, 2002, through December 31, 2006), 67 patients with S. aureus bacteremia and bacteriuria were identified, and control sampling yielded 268 bacteremic, non - bacteriuric patients. Following chart reviews and application of exclusion criteria, there were
61 cases and 247 controls. Of all 308 episodes of bacteremia, 128 (41.6\%) were due to MRSA.

The mean age of pooled dataset, created by joining case and control patients was 48.3 years; $68.5 \%$ were male, 181 (58.8\%) were African-American, and 37 (12.0\%) died during hospital admission. Sites involved 
Table 2 Multiple Cox regression analysis of factors predictive of death among patients with $S$. aureus bacteremia with one contemporaneous urine culture obtained

\begin{tabular}{lll}
\hline Risk factor & Hazard Ratio (95\% Cl) & P value \\
\hline Urine culture positive for S. aureus & $2.87(1.411-5.851)$ & 0.004 \\
\hline Bladder catheter present & $1.96(0.966-3.965)$ & 0.063 \\
\hline Line infection/phlebitis & $0.268(0.060-1.199)$ & 0.085 \\
\hline Charlson score & $1.183(1.063-1.316)$ & 0.018 \\
\hline
\end{tabular}

by bacteremia were cardiac valves [31 (10.7\%)], vascular catheters [59 (19.2\%)], skin/soft tissue [57 (18.5\%)], bone/joints [27 (8.8\%)], lungs [41 (13.3\%)], genitourinary tracts [22 (7.1\%)], and other sites [11 (3.6\%)]; for 106 (36.7\%) patients, there was no documented organ involvement other than bloodstream.

Hospital mortality rates were higher in S. aureus bacteremia patients with bacteriuria compared to patients without bacteriuria ( $39 \%$ vs $17 \%$, respectively, $\mathrm{p}=0.002$ ) (table 1). In multiple Cox regression (table 2), significant predictors of death were positive urine culture (Hazard ratio 2.9; 95\% CI, 1.4-5.9, $\mathrm{p}=0.004)$, indwelling bladder catheter $(2.0 ; 95 \% \mathrm{CI}, 0.97-4.0, \mathrm{p}=0.06)$, and Charlson score (1.2; 95\% CI, 1.1-1.3, $\mathrm{p}=0.02)$; vascular catheter infection or phlebitis was associated with lower risk of death $(0.27 ; 95 \% \mathrm{CI}, 0.060-1.2, \mathrm{p}=0.09)$. Cox regression showed a significantly higher mortality rate in case than in control patients (figure 1). Neither methicillin-resistance nor the specific strain types of MRSA were predictors of mortality in univariate or multivariable analysis.

More positive urine cultures were seen in communityonset (both community-acquired and healthcare-associated) compared to hospital-acquired bacteremia (46\% vs $23 \%$, respectively, $\mathrm{p}<0.001$ ); in HIV-positive patients

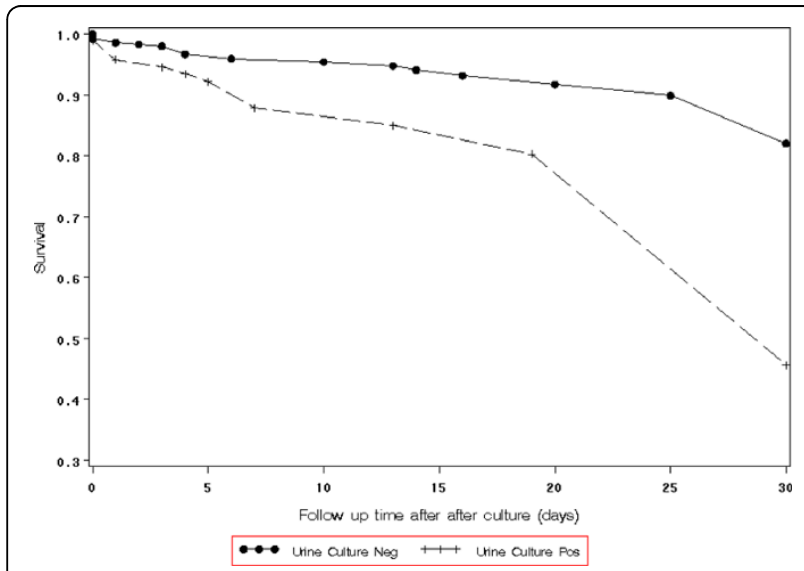

Figure 1 Cox regression for survival analysis for $S$. aureus bacteremia patients with and without bacteriuria ( $p$ value $=$ 0.004). compared to HIV-negative patients $(19 \%$ vs $10 \%, \mathrm{p}=$ $0.05)$; and in patients with recent urological surgery $(11 \%$ vs $3 \%, p=0.03)$ or genitourinary infection $(21 \%$ vs $4 \%, \mathrm{p}<0.001)$ compared with those without genitourinary problems (table 3 ). In multivariable analysis (table $4)$, urological surgery (OR 4.5, $\mathrm{p}=0.045)$ and genitourinary infection (OR $5.7, \mathrm{p}=0.002)$ were significantly associated with positive urine cultures.

\section{Discussion}

In our case-control study, patients who had $S$. aureus bacteremia and a positive urine culture for $S$. aureus had significantly higher mortality than did bacteremic patients with a negative urine culture. This was true even after adjustment for multiple covariates including use of bladder catheters, presence or absence of lower urinary tract symptoms, or recent urological surgeries, which are known risk factors for a positive urine culture, significant factor in the multivariable analysis such as presence of line infection or phlebitis or presence of comorbidities as measured by the Charlson score $[2,11]$. The conclusion that $S$. aureus bacteriuria patients have worse prognosis compared to patients without $S$. aureus bacteriuria among $S$. aureus bacteremia patients may be useful to clinicians when deciding whether to monitor a patient on the ward or the ICU and when explaining the prognosis of the illness to the patient and his family.

$S$. aureus is a common pathogen in the community and in hospitals. $S$ aureus causes significant mortality and morbidity but is an infrequent cause of urinary tract infection [27]. In patients with S. aureus bacteremia, a positive urine culture is typically attributed to ascending infection or to hematogenous spread. Predictors of a positive urine culture for $S$. aureus include presence of indwelling bladder catheters, urinary tract obstruction, instrumentation, or surgery $[27,28]$. We hypothesized that $S$. aureus appears in the urine in bacteremic patients because of higher burden of organisms and thus may portend worse outcome.

A recent study examining the relationship of bacteriuria with mortality found a two-fold increased risk of death in patients with concomitant $S$. aureus bacteriuria and bacteremia [17]. The current study adds to published literature by including significant numbers of methicillin-resistant isolates and by using statistical methods appropriate for varying time at risk. The association of bacteriuria with increased risk of mortality even after adjustment for comorbidities was similar in both studies, suggesting that bacteriuria provides useful prognostic information in the setting of $S$. aureus bacteremia. In addition, based on our findings, it appears that this is an effect independent of methicillin-resistance and that secular trends in incidence of MRSA are unlikely to alter this association. 
Table 3 Univariate analysis of risk factors for bacteriuria among patients with S. aureus bacteremia

\begin{tabular}{|c|c|c|c|c|}
\hline Risk Factor $^{a}$ & Urine culture positive & Urine culture negative & OR $(95 \% \mathrm{Cl})$ & $P$ value \\
\hline N & 57 & 232 & & \\
\hline \multicolumn{5}{|l|}{ Demographics } \\
\hline Age & $49.1(13.8)$ & $47.9(13.8)$ & & 0.59 \\
\hline Male & $40(70)$ & $158(68)$ & & 0.76 \\
\hline Race/Ethnicity & & & & 0.10 \\
\hline Black & $26(46)$ & $141(61)$ & & \\
\hline Hispanic & $14(25)$ & $39(17)$ & & \\
\hline Other Race & $4(7)$ & $21(9)$ & & \\
\hline White & $13(22)$ & $31(13)$ & & \\
\hline \multicolumn{5}{|l|}{ Microbiological factor } \\
\hline \multicolumn{5}{|l|}{ Epidemiological Risk } \\
\hline Community onset & $26(46)$ & $54(23)$ & & $<0.001$ \\
\hline Healthcare associated & $18(32)$ & $61(26)$ & & \\
\hline Hospital onset & $13(23)$ & $117(50)$ & & \\
\hline MRSA & $21(37)$ & $99(43)$ & & 0.42 \\
\hline \multicolumn{5}{|l|}{ Clinical Factors } \\
\hline Immunosuppressed & $9(16)$ & $44(19)$ & & 0.58 \\
\hline Incubation Period & $15.7(30.5)$ & $13.8(33.4)$ & & 0.68 \\
\hline Charlson Score & 2.05 & 2.15 & & 0.801 \\
\hline Hemodialysis & $3(5)$ & $24(10)$ & & 0.24 \\
\hline HIV & $11(19)$ & $23(10)$ & $2.17(1.00-4.77)$ & 0.05 \\
\hline Endocarditis & $7(12)$ & $17(7)$ & & 0.22 \\
\hline Bladder catheter & $20(35)$ & $85(37)$ & & 0.83 \\
\hline Urological surgery & $6(11)$ & $7(3)$ & $3.78(1.22-11.73)$ & 0.03 \\
\hline $\mathrm{DM}$ & $19(33)$ & $64(28)$ & & 0.39 \\
\hline IVDA & $7(12)$ & $39(17)$ & & 0.40 \\
\hline Prosthetic device & $11(19)$ & $55(24)$ & & 0.48 \\
\hline Alcoholism & $11(19)$ & $36(16)$ & & 0.49 \\
\hline Line infection/phlebitis & $6(11)$ & $52(22)$ & $0.41(0.17-1.00)$ & 0.05 \\
\hline Skin soft tissue infection & $10(18)$ & $47(20)$ & & 0.64 \\
\hline Bone/joint infection & $7(12)$ & $20(9)$ & & 0.39 \\
\hline Pulmonary infection & $12(21)$ & $29(13)$ & $1.87(0.89-3.94)$ & 0.10 \\
\hline GU infection & $12(21)$ & $10(4)$ & $5.92(2.41-14.54)$ & $<0.001$ \\
\hline
\end{tabular}

Footnotes: ${ }^{2}$ Data represent count (\%) and mean(standard deviation) for count and continuous data, respectively.

There are several limitations to our study. The patients in the study were cared for at a single center and it may be difficult to generalize our findings to other hospitals. The Cook County Bureau of Health Services is the largest provider of indigent care in Cook County and has seen large increases in rates of community-associated S. aureus infection, and our estimates likely represent robust measures of risk for mortality. A second limitation is that this was a retrospective study and depended on documentation in the chart, which may have resulted in misclassification errors in assessing comorbidities and other covariates. Non-differential misclassification tends to bias towards the null, which suggests that our estimates of risk are likely conservative. In addition, electronic data were used in this study and were prospectively collected at the time of care; these data were not subject to problems inherent in reviews of written documentation Finally, in our study, we had an overall mortality rate of $12 \%$ which was at the lower end of published mortality rates-12-46\% [3-13,27,29,30]-in this setting, suggesting that our cohort may have had fewer comorbidities and lower attributable mortality 
Table 4 Multiple Cox regression analysis of risk factors for bacteriuria in patients with $S$. aureus bacteremia

\begin{tabular}{lll}
\hline Risk factor & OR $(\mathbf{9 5 \%} \mathbf{C l})$ & P value \\
\hline Urological surgery & $4.47(1.03-19.30)$ & 0.045 \\
\hline GU infection & $5.70(1.90-17.12)$ & 0.002 \\
\hline
\end{tabular}

Factors included in Backward LR analysis: location of acquired infection (community-acquired vs hospital-acquired vs healthcare-associated); race; urological surgery; presence of lung infection; presence of genitourinary tract infection; duration of bloodstream infection

that in other published data. This may be a result of the significant burden of CA-MRSA in our patient population.

\section{Conclusions}

In patients with $S$. aureus bacteremia, a positive urine culture for $S$. aureus may be used to identify patients at higher risk of death. Patients who have S. aureus bacteremia and more comorbidities are at increased risk for higher mortality rate.

\section{Acknowledgements}

We thank Izumi Chihara for assistance with statistical analysis. Financial support: This study was funded in part by the CDC Chicago EpiCenter Grant Number 5U01C1000327.

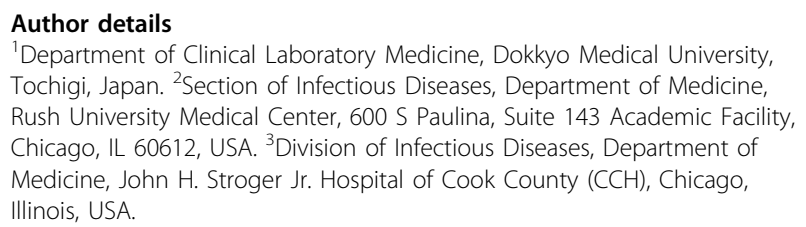

\section{Authors' contributions}

SC participated in the design of the study, performed the chart reviews, participated in some statistical analysis and drafted the manuscript. KJP participated in obtaining the data for the study and proofreading the manuscript. RAW participated in the design of the study and proofreading the manuscript. BH participated in the design of the study, performed statistical analysis and proofread the manuscript. All authors read and approved the final manuscript.

\section{Competing interests}

Bala Hota is a member of the speaker's bureau for Pfizer. All other authors have no competing interests.

Received: 13 July 2009 Accepted: 29 July 2010 Published: 29 July 2010

\section{References}

1. Lee BK, Crossley K, Gerding DN: The association between Staphylococcus aureus bacteremia and bacteriuria. Am J Med 1978, 65(2):303-306.

2. Lesens $O$, Methlin C, Hansmann Y, Remy V, Martinot M, Bergin C, Meyer P, Christmann D: Role of comorbidity in mortality related to Staphylococcus aureus bacteremia: a prospective study using the Charlson weighted index of comorbidity. Infect Control Hosp Epidemiol 2003, 24(12):890-896.

3. Shurland S, Zhan M, Bradham DD, Roghmann MC: Comparison of mortality risk associated with bacteremia due to methicillin-resistant and methicillin-susceptible Staphylococcus aureus. Infect Control Hosp Epidemiol 2007, 28(3):273-279.

4. Kaech C, Elzi L, Sendi P, Frei R, Laifer G, Bassetti S, Fluckiger U: Course and outcome of Staphylococcus aureus bacteraemia: a retrospective analysis of 308 episodes in a Swiss tertiary-care centre. Clin Microbiol Infect 2006, 12(4):345-352.
5. Blot SI, Vandewoude KH, Hoste EA, Colardyn FA: Outcome and attributable mortality in critically III patients with bacteremia involving methicillinsusceptible and methicillin-resistant Staphylococcus aureus. Arch Intern Med 2002, 162(19):2229-2235.

6. Soriano A, Martinez JA, Mensa J, Marco F, Almela M, Moreno-Martinez A, Sanchez F, Munoz I, Jimenez de Anta MT, Soriano E: Pathogenic significance of methicillin resistance for patients with Staphylococcus aureus bacteremia. Clin Infect Dis 2000, 30(2):368-373.

7. Jensen $A G$, Wachmann $C H$, Poulsen $K B$, Espersen F, Scheibel J, Skinhoj $P$, Frimodt-Moller N: Risk factors for hospital-acquired Staphylococcus aureus bacteremia. Arch Intern Med 1999, 159(13):1437-1444.

8. Mylotte JM, Tayara A: Staphylococcus aureus bacteremia: predictors of 30-day mortality in a large cohort. Clin Infect Dis 2000, 31(5):1170-1174.

9. McClelland RS, Fowler VG, Sanders LL, Gottlieb G, Kong LK, Sexton DJ, Schmader K, Lanclos KD, Corey R: Staphylococcus aureus bacteremia among elderly vs younger adult patients: comparison of clinical features and mortality. Arch Intern Med 1999, 159(11):1244-1247.

10. Laupland KB, Church DL, Mucenski M, Sutherland LR, Davies HD: Population-based study of the epidemiology of and the risk factors for invasive Staphylococcus aureus infections. J Infect Dis 2003, 187(9):1452-1459.

11. Bader MS: Staphylococcus aureus bacteremia in older adults: predictors of 7-day mortality and infection with a methicillin-resistant strain. Infect Control Hosp Epidemiol 2006, 27(11):1219-1225.

12. Gomez J, Garcia-Vazquez E, Banos R, Canteras M, Ruiz J, Banos V, Herrero JA, Valdes M: Predictors of mortality in patients with methicillinresistant Staphylococcus aureus (MRSA) bacteraemia: the role of empiric antibiotic therapy. Eur J Clin Microbiol Infect Dis 2007, 26(4):239-245.

13. Romero-Vivas J, Rubio M, Fernandez C, Picazo Jj: Mortality associated with nosocomial bacteremia due to methicillin-resistant Staphylococcus aureus. Clin Infect Dis 1995, 21(6):1417-1423.

14. Desachy A, Lina G, Vignon P, Hashemzadeh A, Denis F, Etienne J, Francois $B$, Ploy MC: Role of superantigenic strains in the prognosis of community-acquired methicillin-susceptible Staphylococcus aureus bacteraemia. Clin Microbiol Infect 2007, 13(11):1131-1133.

15. Fowler VG, Sanders LL, Sexton DJ, Kong L, Marr KA, Gopal AK, Gottlieb G, McClelland RS, Corey GR: Outcome of Staphylococcus aureus bacteremia according to compliance with recommendations of infectious diseases specialists: experience with 244 patients. Clin Infect Dis 1998, 27(3):478-486.

16. Jensen AG, Wachmann CH, Espersen F, Scheibel J, Skinhoj P, FrimodtMoller N: Treatment and outcome of Staphylococcus aureus bacteremia: a prospective study of 278 cases. Arch Intern Med 2002, 162(1):25-32.

17. Huggan PJ, Murdoch DR, Gallagher K, Chambers ST: Concomitant Staphylococcus aureus bacteriuria is associated with poor clinical outcome in adults with S. aureus bacteraemia. J Hosp Infect 2008, 69(4):345-349.

18. Ganz T: Defensins in the urinary tract and other tissues. J Infect Dis 2001, 183(Suppl 1):S41-42.

19. Svanborg C, Bergsten G, Fischer H, Godaly G, Gustafsson M, Karpman D, Lundstedt AC, Ragnarsdottir B, Svensson M, Wullt B: Uropathogenic Escherichia coli as a model of host-parasite interaction. Curr Opin Microbiol 2006, 9(1):33-39.

20. De NS: Experimental pyelonephritis in the rabbit produced by staphylococcal infection. J Pathol Bacteriol 1950, 62(3):429-436.

21. National Nosocomial Infections Surveillance (NNIS) System Report, data summary from January 1992 through June 2003, issued August 2003. Am J Infect Control 2003, 31(8):481-498.

22. Fridkin SK, Hageman JC, Morrison M, Sanza LT, Como-Sabetti K, Jernigan JA, Harriman K, Harrison LH, Lynfield R, Farley MM: Methicillin-resistant Staphylococcus aureus disease in three communities. N Engl J Med 2005, 352(14):1436-1444.

23. Hota B, Ellenbogen C, Hayden MK, Aroutcheva A, Rice TW, Weinstein RA: Community-associated methicillin-resistant Staphylococcus aureus skin and soft tissue infections at a public hospital: do public housing and incarceration amplify transmission? Arch Intern Med 2007, 167(10):1026-1033.

24. King MD, Humphrey BJ, Wang YF, Kourbatova EV, Ray SM, Blumberg HM: Emergence of community-acquired methicillin-resistant Staphylococcus aureus USA 300 clone as the predominant cause of skin and soft-tissue infections. Ann Intern Med 2006, 144(5):309-317. 
25. Deyo RA, Cherkin DC, Ciol MA: Adapting a clinical comorbidity index for use with ICD-9-CM administrative databases. J Clin Epidemiol 1992, 45(6):613-619.

26. Naimi TS, LeDell KH, Como-Sabetti K, Borchardt SM, Boxrud DJ, Etienne J, Johnson SK, Vandenesch F, Fridkin S, O'Boyle C, et al: Comparison of community- and health care-associated methicillin-resistant Staphylococcus aureus infection. JAMA 2003, 290(22):2976-2984.

27. Demuth PJ, Gerding DN, Crossley K: Staphylococcus aureus bacteriuria. Arch Intern Med 1979, 139(1):78-80.

28. Arpi M, Renneberg J: The clinical significance of Staphylococcus aureus bacteriuria. J Urol 1984, 132(4):697-700.

29. Hawkins C, Huang J, Jin N, Noskin GA, Zembower TR, Bolon M: Persistent Staphylococcus aureus bacteremia: an analysis of risk factors and outcomes. Arch Intern Med 2007, 167(17):1861-1867.

30. Mylotte JM, McDermott C, Spooner JA: Prospective study of 114 consecutive episodes of Staphylococcus aureus bacteremia. Rev Infect Dis 1987, 9(5):891-907.

\section{Pre-publication history}

The pre-publication history for this paper can be accessed here: http://www.biomedcentral.com/1471-2334/10/225/prepub

doi:10.1186/1471-2334-10-225

Cite this article as: Chihara et al: Staphylococcus aureus bacteriuria as a prognosticator for outcome of Staphylococcus aureus bacteremia: a case-control study. BMC Infectious Diseases 2010 10:225.

\section{Submit your next manuscript to BioMed Central} and take full advantage of:

- Convenient online submission

- Thorough peer review

- No space constraints or color figure charges

- Immediate publication on acceptance

- Inclusion in PubMed, CAS, Scopus and Google Scholar

- Research which is freely available for redistribution

Submit your manuscript at www.biomedcentral.com/submit 